\title{
Anaemia - a pale ale?
}

\section{GL Muntingh, ${ }^{\text {" }}$ M Viljoen ${ }^{2}$}

${ }^{1}$ Department of Pharmacology, School of Medicine, Faculty of Health Sciences, University of Pretoria

${ }^{2}$ Department of Pharmacology and Clinical Pharmacy, School of Pharmacy, Faculty of Natural Sciences, University of the Western Cape

*Corresponding author, email: george.muntingh@up.ac.za

\section{Abstract}

Despite some modest improvements described recently, anaemia remains a significant global public health concern affecting both developed and developing countries. It affects a quarter of the global population, including 293 million (47\%) children who are younger than five years of age. A prevalence of $42 \%$ and $30 \%$ has been described in pregnant and non-pregnant women, respectively. Children and women of reproductive age are at high risk, partly because of physiological vulnerability, followed by the elderly. Africa and Asia are the most heavily affected regions, accounting for $85 \%$ of the absolute anaemia burden in highrisk groups. According to the World Health Organization global database on anaemia (1993-2005), this disorder was considered to be a moderate public health problem in South African preschool children, pregnant women and non-pregnant women of reproductive age.

There has been an increased awareness of anaemia and its consequences on the health and development of women and children in the past few decades. The many underlying causes of the various types of anaemia seen in general practice means it is essential that practitioners' clinical decisions be underpinned by a sound knowledge of the pathological processes involved. Thorough history-taking will guide practitioners to request specific tests to confirm or refute differential diagnoses. Management must be developed around the specific type of anaemia and the potential physical and psychological effects it may have on the individual.

Keywords: anaemia, blood film, evaluation, macrocytic, microcytic

\section{Anaemia: Introduction}

"Bloody relief to me this is, thanks pal!' Olly had ... 'Rubbish! Try lager Boris, it'll put hairs on your chest, bloody hell, pale ale? Sounds anaemic for a starter."'

From "Planet of the Publishers" by Jim Ore, p. 95.

Cited as the most common nutritional disorder on the planet, it is likely that your patients could experience anaemia at some point in their life.

The word "anaemia" (also spelled anemia) is composed of two Greek roots that together mean "without blood", but to use this literal translation as a definition would be a gross exaggeration. Still, the modern definition is simple: anaemia is any condition characterised by an abnormal decrease in the body's total red blood cell mass.

\section{Historical perspective}

The ancients readily recognised the importance of blood as a lifegiving substance, believing it to hold the body's vital force. While today the concept of the circulation of the blood seems obvious, it was not until the relatively recent era of the seventeenth century that William Harvey (Figure 1), also known for 'De Motu Cordis' ("On the Motion of the Heart and Blood"), determined that blood was not just a contained static liquid.'

The scientific study of blood had to await the invention of the microscope. No one thought to use this instrument to look at blood until the noted Dutch naturalist Jan Swammerdam (1637-80) (Figure 2) turned his instrument on the fluid of

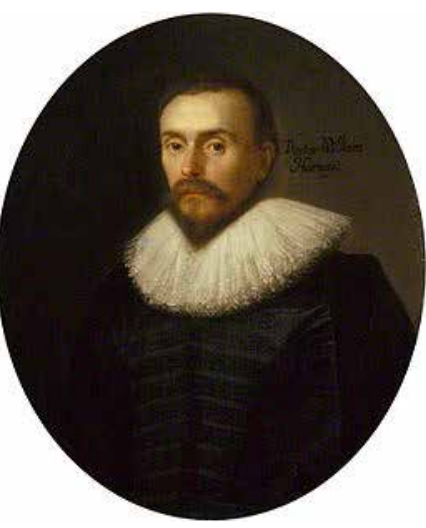

Figure 1. William Harvey

(Courtesy: https://en.wikipedia.org/wiki/William_Harvey\#cite_note-30. Accessed 3 May 2017) 


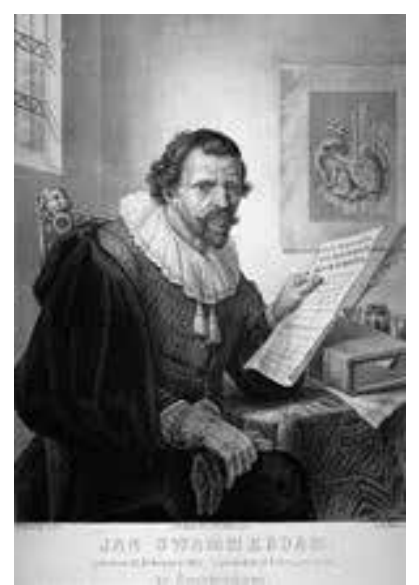

Figure 2. Jan Swammerdam

(Courtesy: https://en.wikipedia.org/ wiki/Jan_Swammerdam. Accessed 3 May 2017)

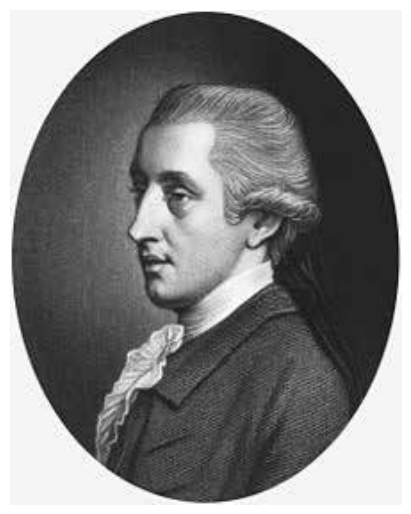

Figure3. William Hewson

(Courtesy: https://en.wikipedia.org/ wiki/William_Hewson_(surgeon) Accessed 9 May 2017)

life and discovered what he called "ruddy globules", which were presumably red blood cells (RBCs). The realisation of "ruddy globules" or RBCs had to await the insight of an English surgeon, anatomist and physiologist, William Hewson (1739-74) (Figure 3), whose posthumously-published opinion, that due to the presence of RBCs in such abundance they had to be important, earned him the title "the father of haematology."

At the beginning of the nineteenth century, the word "anaemia" was a clinical term referring to pallor of the skin and mucous membranes (the thin linings that cover the inside of the mouth, the whites of the eyes, the inner surface of the eyelids, and other surfaces not covered by skin). At the time of the publication of the first textbook of haematology by the French physician Gabriel Andral in 1843, there was no appreciation for the basic concept held today that clinical anaemia is due to inadequate numbers of RBCs. ${ }^{2}$ Before this could be determined, it was necessary to develop a technical method by which blood cells could be counted. This was first done in 1852 by Karl Vierordt, but his technique was too tedious to gain widespread use. Vierordt's student, H. Welcher, counted the blood cells in a patient with chlorosis (an old term for what is probably our modern irondeficiency anaemia) and found in 1854 that an anaemic patient had significantly fewer red blood cells than a healthy person. ${ }^{2}$ Thus, almost two centuries passed after Swammerdam's discovery of red blood cells in 1658 before it was shown that a deficiency in the number of RBCs was the basis for the clinical diagnosis of anaemia.

\section{General Overview}

Despite some modest improvements described recently, ${ }^{3}$ anaemia remains a significant global public health concern affecting both developed and developing countries. The World Health Organization (WHO) prevalence of anaemia (1993-2005) reported that it affected a quarter of the global population, including 293 million (47\%) children who were younger than five years of age. A prevalence of $42 \%$ and $30 \%$ was described in pregnant and non-pregnant women, respectively. ${ }^{4}$

A finding of anaemia based on a full blood count is very often an incidental finding and also only the first step of a series of investigations for most patients. There has been an increased awareness of anaemia and its consequences on the health and development of women and children in the past few decades. At the 65th World Health Assembly in 2012, an action plan and global targets for maternal, infant and child nutrition were approved, with a commitment to reduce anaemia prevalence by $50 \%$ in women of reproductive age by 2025 , compared to the baseline set in the period 1993-2005. ${ }^{5}$ Although a more recent systematic analysis ${ }^{3}$ of population-representative data indicated a modest improvement in haemoglobin levels and a global reduction in anaemia prevalence (from 1995-2011), the war is far from won, if the said targets are to be met timeously. Furthermore, anaemia prevalence remains unacceptably high in the poorest regions of the world. ${ }^{1}$

Anaemia is also one of the most frequent haematological complications seen in people with human immuno-deficiency virus (HIV) and acquired immuno-deficiency syndrome (AIDS). ${ }^{6,7}$ Among HIV infected individuals, the prevalence of anaemia at initiation of antiretroviral therapy (ART) is reported to range between $20-90 \%$ in different clinical settings. ${ }^{8-10}$ Anaemia in HIV infected individuals has multifactorial aetiologies which complicate its differential diagnosis and treatment.

It has been demonstrated that haemoglobin levels provide prognostic information independent of that provided by the CD4 lymphocyte count and HIV viral load ${ }^{11}$ and the presence of anaemia has been shown to be a significant predictor of progression to AIDS and is independently associated with an increased risk of death..$^{911-15}$ Conversely, recovery from anaemia among HIV-infected patients has been shown to be associated with decreased risk of disease progression to approximately the same level as in patients who have never had anaemia. ${ }^{16}$ In addition, recovery from anaemia is associated with improved survival. ${ }^{17,18}$ Although the burden of anaemia among HIV infected patients has reduced since the introduction of $A R T^{6,9}$ anaemia remains prevalent even among patients on ART, with approximately $18-46 \%$ of patients, anaemic one year after initiating $\mathrm{ART}^{14}$ and it continues to be a common contributor of morbidity and mortality. ${ }^{12}$

Anaemia is defined as a decrease in the total number of RBCs or haemoglobin in the blood..$^{19,20}$ It can also be defined as a lowered ability of the blood to carry oxygen. ${ }^{21}$ When anaemia exhibits a slow onset, symptoms are often vague and may include lethargy, general weakness, shortness of breath or a poor ability to exercise. Quick onset anaemia often has greater symptoms, which may include confusion, loss of consciousness, or increased thirst. Anaemia must be significant before a person 
becomes noticeably pale. Additional symptoms may occur depending on the underlying cause (Table 1).22

Diagnosis of anaemia is defined by the World Health Organization as $\mathrm{Hb}<13 \mathrm{~g} / \mathrm{dL}(<130 \mathrm{~g} / \mathrm{L} ;<8.07 \mathrm{mmol} / \mathrm{L})$ in men and $<12 \mathrm{~g} / \mathrm{dL}$ ( $<120 \mathrm{~g} / \mathrm{L} ;<7.45 \mathrm{mmol} / \mathrm{L})$ in women. ${ }^{22}$ Further testing is then required to determine the cause. ${ }^{23}$

Table 1

Clinical presentation of anaemia to be considered:

- Timing of symptoms such as tiredness/lethargy, chronic/acute episode

- Breathlessness: at rest/on exertion

- Dizziness

- Syncope

- Signs of cardiac failure

- Palpitations/chest pain

- Family history of anaemia

- Heavy menstrual bleeds

- Past medical history, for example, haemorrhoids

- Altered bowel habits

- Blood in stool, rectal bleeding

- Pallor

- Pale conjunctivae

- Poor growth

- Weakness

- Listlessness

\section{Causes and classification}

The causes of anaemia may be ${ }^{19}$ :

- Impaired RBC production where causes include iron deficiency, a lack of vitamin B12, thalassemia, and a number of neoplasms of the bone marrow

- Increased RBC destruction (haemolytic anaemias) where causes can include a number of genetic conditions such as sickle cell anaemia, infections, e.g. malaria, and certain autoimmune diseases

- Blood loss where common causes include trauma, gastrointestinal bleeding, abnormal menstrual cycle, among others.
Several of the above mechanisms may interplay to cause anaemia eventually. Indeed, the most common cause of anaemia is blood loss, but this usually does not cause any lasting symptoms unless a relatively impaired $\mathrm{RBC}$ production develops, in turn most commonly by iron deficiency. ${ }^{20}$

Anaemia can also be classified based on the size of the RBCs and number of haemoglobin in each cell (Figure 4). If the RBCs are small, it is microcytic anaemia. If they are large, it is macrocytic anaemia, while if they are normal sized, it is normocytic anaemia. ${ }^{20}$

The first step in diagnosis is to identify the type of anaemia that is present (Figure 5), using the results of the full blood count (FBC). Due to their relative reproducibility, mean corpuscular volume (MCV) and red cell width (RDW) are the most useful components in the initial classification of most anaemias ${ }^{21}$ :

- Microcytic (MCV < 80 femtolitres [fL]): serum iron studies should be performed.

- Normocytic (MCV 80-100 femtolitres [fL]): the reticulocyte count should be examined to determine whether the anaemia is hypoproliferative $(<2 \%)$ or hyperproliferative ( $2 \%)$.

- Macrocytic (MCV > 100 femtolitres [fL]): the peripheral smear should be examined for megaloblasts and hypersegmented neutrophils. If these cells are present, the anaemia is megaloblastic. If they are absent, the anaemia is nonmegaloblastic (liver disease, hypothyroidism, alcoholism and haemolysis).

Functional classification of anaemia includes hypoproliferative, maturing disorders and haemorrhage (haemolysis) which can then also be further sub-classified.22

\section{Selective discussion on more specific types of anaemia}

\section{Iron deficiency anaemia (IDA)}

Blood tests show low iron and ferritin levels and an elevated total iron binding capacity. ${ }^{22}$ The RBCs can appear hypochromic and

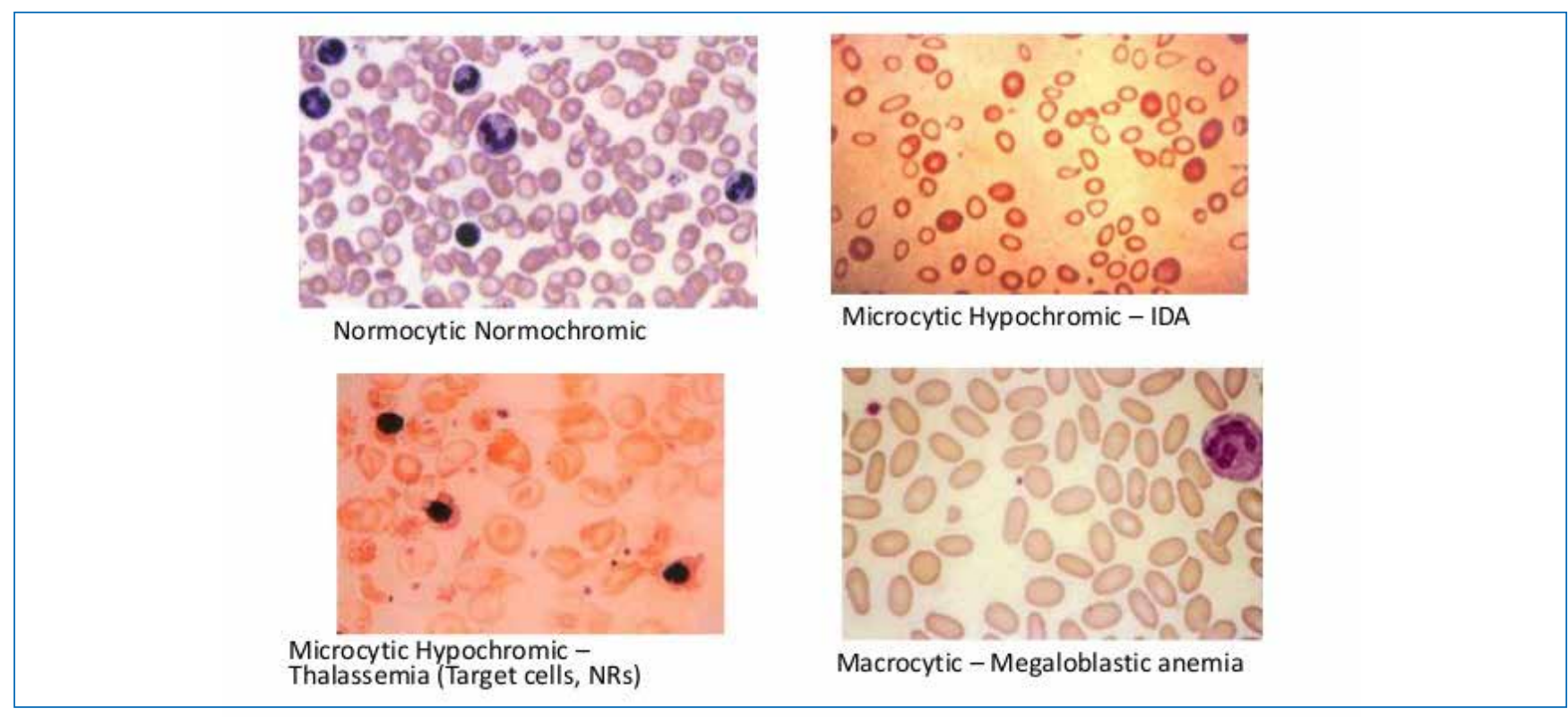

Figure 4. Anaemia can also be classified based on the size of red blood cells (Courtesy: http://www.australianhospitals.net/anemia/how-to-treat-microcytic-anemia._Accessed 13 April 2017) 


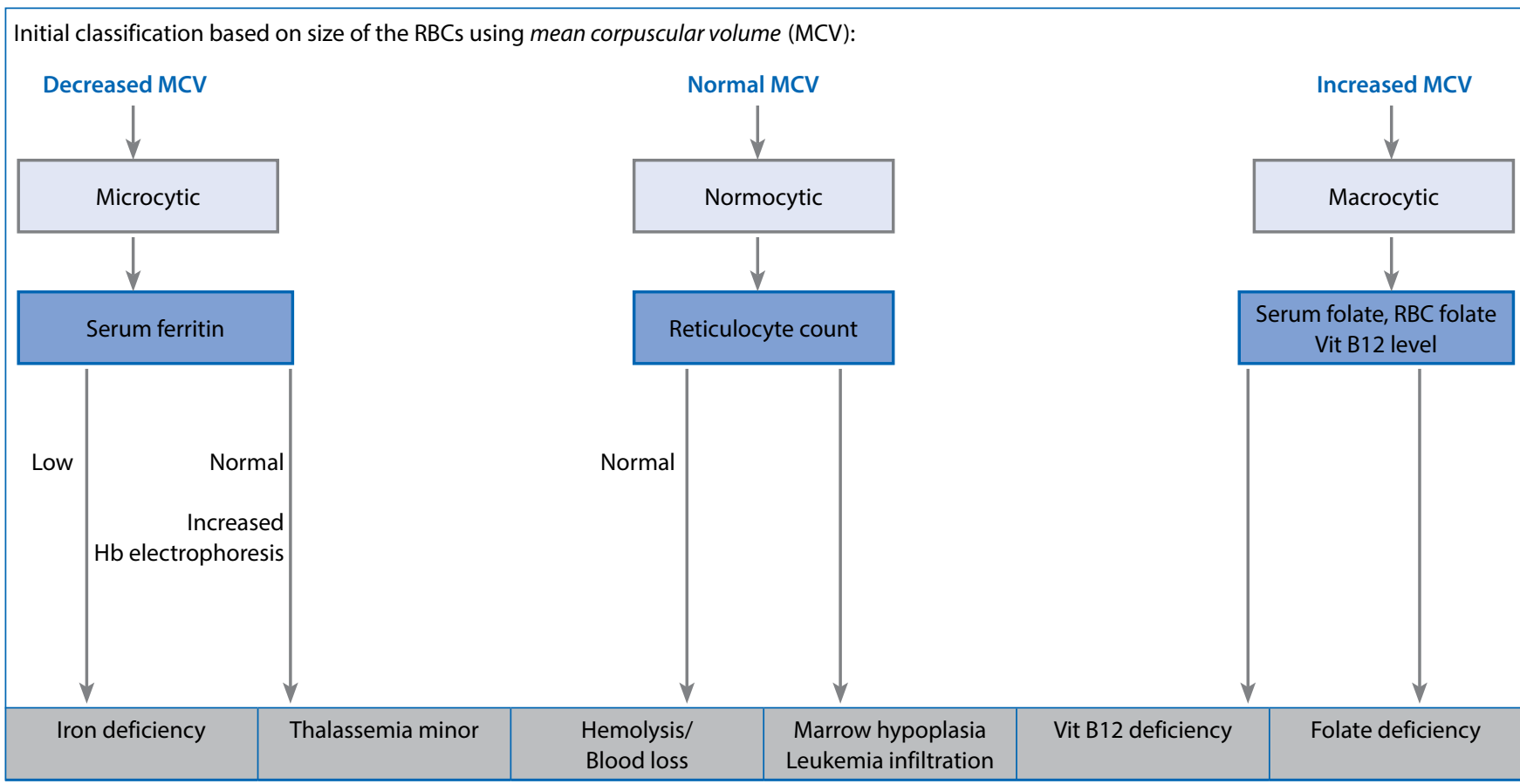

Figure 5. Diagnosis and identifying the type of anaemia

have reduced mean cell haemoglobin $(\mathrm{MCH})$ and reduced $\mathrm{MCV}$ known as microcytosis. ${ }^{23}$

A family history of IDA, poor diet, genetic factors and bleeding disorders can contribute to this type of anaemia. Studies have shown that blood levels of vitamins, folate and iron are lower in children of families with low income due to poor nutrition. ${ }^{24}$ Poverty is not the only contributing factor to IDA. Some ethnic minority groups, including African-Caribbean, Asian and Chinese people are more likely to have this form of anaemia. ${ }^{25}$ Further, studies on infant feeding have shown that early introduction to cow's milk is associated with IDA compared to babies breast fed over a longer period or who have been given formula milk containing fortified iron. ${ }^{26}$

Infants with IDA may present with growth retardation, delay in psychomotor and cognitive development and may be prone to recurrent infections. The causative factor for these discrete symptoms is often missed in children as they are not as acute as the signs presented by an adult with IDA, which include dizziness, malaise, pallor and breathlessness.

It is essential that practitioners explore dietary plans with parents to promote healthy growth and development in children. For example, promoting breastfeeding where iron in breast milk is readily absorbed, giving advice on weaning, and encouraging fruits rich in vitamin $C$ which facilitates better iron absorption to reduce IDA in infants. ${ }^{26}$

Adults over the age of 45 who present with IDA should be investigated for underlying pathologies. IDA in adults is often linked to gastrointestinal bleeds, malignancies, or coeliac disease. ${ }^{27}$ Referral for upper gastrointestinal investigation such as endoscopy and lower bowel explorations such as barium enema and colonoscopy may be essential to determine the causative factor of IDA.
In general, if dietary history is strongly suggestive of irondeficiency, modify diet and provide iron supplementation (if $\mathrm{Hb}<10 \mathrm{~g} / \mathrm{dl}$, or low ferritin even if $\mathrm{Hb}$ is normal). Concurrent vitamin $\mathrm{C}$ will encourage iron absorption. Arrange follow-up to ensure appropriate response to treatment. Dietary advice could include increase in the consumption of red meat, chicken, fish, pulses and green vegetables. ${ }^{26}$

\section{Pernicious anaemia}

In this situation, tests reveal a deficiency in vitamin B12, which is required for normal RBC synthesis. Deficiency can be caused by poor diet, alcoholism, malabsorption through, for example, Crohn's disease, and reduction in intrinsic factor (also caused by antibodies active against it). Patients might exhibit neurological symptoms such as numbness and paresthesia. In extreme cases, reversible dementia and optic neuropathy are associated with vitamin B12 deficiency. Management should include encouraging vitamin B12 rich foods such as fish, meat and dairy products. ${ }^{28}$

Treatment includes high doses of oral or intramuscular (IM) vitamin B12. Both routes are equally effective, so should reflect the patients' choice. ${ }^{29}$ However, if the deficiency is due to gastrointestinal problems, such as a lack of intrinsic factor, then IM injections should be considered as vitamin B12 will not be absorbed through the ileum. The treatment regime varies and depends on the severity of symptoms. Initial dose regime may be 800 mcg- 1 mg IM daily for two weeks followed by 1 mg every three months for life. Treatment in the absence of neurological symptoms is $1 \mathrm{mg}$ IM three times weekly for two weeks, and then $1 \mathrm{mg}$ every three months. For pernicious anaemia with neurological symptoms, $1 \mathrm{mg}$ should be given every alternate day until stores are replenished. ${ }^{29}$ 


\section{Anaemia due to excessive blood loss}

Gastrointestinal ulcers and menorrhagia can contribute to excessive blood loss resulting in anaemia. Heavy menstrual bleeding is a common presentation in general practice, and many women describe chronic fatigue and an inability to cope with daily activities.

A FBC often reveals iron deficiency anaemia that is a consequence of heavy menstrual bleeding. Treating the cause of excessive blood loss and correcting the anaemia through dietary advice and iron supplements should improve patients' overall quality of life. Persistent gastrointestinal bleeding from ulceration can be subtle and patients might present with symptoms such as breathlessness and tiredness. Further investigations such as endoscopy may reveal an underlying cause that will need to be managed. ${ }^{29}$

\section{Haemolytic anaemia}

This condition is characterised by premature destruction of RBCS where the bone marrow is unable to compensate for RBC loss. The life cycle of RBCs is reduced and as the bone marrow attempts to increase production an elevated level of reticulocytes may be seen in the blood. Early haemolysis also result in folate and vitamin B12 deficiencies.

Underlying causes for this condition include autoimmune disorders, infection, and inherited factors such as sickle cell disorder and thalassaemia. ${ }^{29}$

Treatment depends on the cause of early haemolysis and replacement of iron and folates. ${ }^{29}$

\section{Aplastic anaemia}

The bone marrow is unable to produce cellular elements such as leucocytes, erythrocytes and platelets; this can be referred as pancytopenia. The condition may be due to a number of causes such as radiation exposure, viral infections such as hepatitis, and autoimmune disorders such as lupus, and is often idiopathic.

Patients might present with unexplained bruising caused by low platelet count, tachycardia and shortness of breath due to reduced RBCs, and increased infections caused by a lowered white cell count. Treatment aims to restore haemopoietic function and bone marrow transplants are often needed. Long term survival and complete remission are more likely to occur in people below the age of $40 .{ }^{30}$

\section{Macrocytic anaemia}

A rise in the MCV of RBCs above the normal range (> $100 \mathrm{fL}$ ). Cells are larger than normal with immature nuclei.

Macrocytic anaemia can occur in conditions such as alcoholism, myeloma and hypothyroidism and can be sub-divided into two categories:

- megaloblastic, that results from a defect in DNA synthesis, and

- non-megaloblastic that occurs as a consequence of underlying disease and can be diagnosed by examining the patient's bone marrow.
Macrocytosis is often asymptomatic but in some instances patients might present with tiredness, mild jaundice, glossitis or neuropathy. Treatment depends on the underlying cause, and investigations such as measuring vitamin B12, folates, liver function tests and reticulocyte count may be required. In some instances, bone marrow examination may be essential. ${ }^{31}$

\section{Drug use associated with Vit B12 deficiencies}

Common medications that are associated with or may cause Vit B12 deficiencies include: ${ }^{32}$

- Colchicine: Antagonist at receptors located in the terminal ileum of the small intestine for which Vit B12/intrinsic factor complexes would bind to for absorption

- Tetracyclines, erythromycin and Isoniazid: decreases absorption of Vit B12

- Ethanol: Impairs intestinal absorption possibly due to effects on the pancreas where it affects the pancreas's ability to secrete proteases necessary to release Vit B12 from R-binders within the duodenum

- Histamine-2 receptor blockers (e.g. ranitidine) and proton pump inhibitors (e.g. lansoprazole): Increasing the gastric $\mathrm{pH}$ can impair the activation of pepsin that is necessary for releasing Vit B12 bound to proteins within the ingested foods

- Metformin: Possibly alterations in calcium-dependant uptake of Vit B12/intrinsic factor complex with in the terminal ileum

- Methotrexate: Interference with DNA metabolism

- Nitrious Oxide: Vit B12 destruction (occupational hazard for anaesthetist and dentist still employing it).

\section{Conclusion}

Despite some modest improvements described recently, anaemia remains a significant global public health concern affecting both developed and developing countries.

While anaemia is a major component of the global burden of disease, its common-place existence across most clinical practices across the world does not necessarily mean that it is easily and adequately diagnosed, evaluated and managed.

The many underlying causes of the various types of anaemia seen in general practice means it is essential that practitioners' clinical decisions be underpinned by a sound knowledge of the pathological processes involved. Thorough history-taking will guide practitioners to request specific tests to confirm or refute differential diagnoses. Management must be developed around the specific type of anaemia and the potential physical and psychological effects it may have on the individual.

\section{References}

1. Regina Bailey. William Harvey - Father of Cardiovascular Medicine. Available from:https://www.thoughtco.com/circulatory-system -pulmonary-and-systemic-circuits-3999090

2. Hajdu SI. The Discovery of Blood Cells. Ann Clin Lab Sci. 2003;33(2):237-8.

3. Stevens GA, Finucane MM, De-Regil LM, et al. Global, regional, and national trends in haemoglobin concentration and prevalence of total and severe anaemia in children and pregnant and non-pregnant women for 1995-2011: a systematic analysis of population representative data. Lancet Glob Health 2013;1:16-25 
4. McLean E, Cogswell M, Egli I, et al. Worldwide prevalence of anaemia, WHO vitamin and mineral nutrition information system, 1993-2005. Public Health Nutr. 2009;12(4):444-54.

5. Branca F, Piwoz E, Schultink W, Martinez Sullivan L. Nutrition and health in women, children, and adolescent girls. BMJ. 2015 [];351:h4173.

6. Adane A, Desta K, Bezabih A, Gashaye A, Kassa D. HIV-associated anaemia before and after initiation of antiretroviral therapy at Art Centre of Minilik II Hospital, Addis Ababa, Ethiopia. Ethiopian Medical Journal. Jan 2012;50(1):13-21.

7. WHO. World Wide Prevalence of Anaemia 1993-2005. De Benoist B, MCLean E, Egli I, Cogswell M, eds. 2008. Geneva, Switzerland.

8. Doukas MA. Human-Immunodeficiency-Virus Associated Anaemia. Medical Clinics of North America. May 1992;76(3):699-709.

9. Owiredu WK, Quaye L, Amidu N, Addai-Mensah O. Prevalence of anaemia and immunological markers among Ghanaian HAART-naive HIV-patients and those on HAART. African Health Sciences. 2011;11(1):2-15.

10. WHO/UNAIDS. Epidemiological Fact Sheet on HIV/AIDS South Africa. 2008. WHO publishing (Switzerland). Accessed 28 April 2017. Available from: http://apps. who.int/globalatlas/predefinedReports/EFS2008/full/EFS2008_ZA.pdf. 19

11. Mocroft A, Kirk O, Barton SE, Dietrich M, Proenca R, Colebunders R, et al. Anaemia is an independent predictive marker for clinical prognosis in HIV-infected patients from across Europe. AIDS. 1999;13(8):943.

12. Alemu AW, Sebastian MS. Determinants of survival in adult HIV patients on antiretroviral therapy in Oromiyaa, Ethiopia. Global Health Action. Oct 2010;3.

13. Ferri RS, Adinolfi A, Orsi AJ, Sterken DJ, Keruly JC, Davis S, et al. Treatment of anemia in patients with HIV Infection--Part 2: guidelines for management of anemia. The Journal of the Association of Nurses in AIDS Care. 2002;13(1):50-9.

14. Masaisa F, Gahutu JB, Mukiibi J, Delanghe J, Philippe J. Anemia in Human Immunodeficiency Virus-Infected and Uninfected Women in Rwanda. Am J Trop Med Hyg. Mar 2011;84(3):456-60.

15. Mildvan D. Implications of anemia in human immunodeficiency virus, cancer, and hepatitis C virus. Clin Infect Dis. 2003;37(4) Supp:S293-S6.

16. Volberding P. Anemia HIVWG. Consensus statement: Anemia in HIV infection - Current trends, treatment options, and practice strategies. Clin Ther. 2000;22(9):1004-20.

17. Sullivan PS, Hanson DL, Chu SY, Jones JL, Ward JW, Adult Adolescent Spectrum Dis $G$. Epidemiology of anemia in human immunodeficiency virus (HIV)-infected persons: Results from the multistate adult and adolescent spectrum of HIV disease surveillance project. Blood. 1998;1;91(1):301-8.

18. Moore RD, Keruly JC, Chaisson RE. Anemia and Survival in HIV Infection. J Acquir Immune Defic Syndr. 1998;19(1):29-33.

19. "What Is Anemia? - NHLBI, NIH". . Available from: www.nhlbi.nih.gov.

20. Rodak, Bernadette F. Hematology : clinical principles and applications (3rd ed.). Philadelphia: Saunders. 2007. p. 220.

21. Assessment of Anemia. BMJ Best Practice. . Available from: http://bestpractice. bmj.com/best-practice/monograph/93/diagnosis.html

22. Cook K; Lyons WL.. Anemias. Pharmacotherapy: A Pathophysiologic Approach, 9th ed. McGraw-Hill Education, 2014. p.1605-24.

23. Lewis SM, Bain BJ, Bates I. Practical Haematology. 9th ed. Churchill Livingstone: London. 2001.

24. Gregory J, Lowe S, Bates CJ, et al. National Diet and Nutritional Survey: Young People Aged 4-18 Years. The Stationery Office: London, 2000.

25. Moy R, Aukett A. Population screening for anaemia in the inner city. Ambulatory Child Health. 2000;6:11-8.

26. Male C, Persson LA, Freeman V, et al: The Euro-Growth Iron Study Group. Prevalence of iron deficiency in 12-month-old infants from 11 European areas and influence of dietary factors on iron status (Euro-Growth Study). Acta Paediatrica. 2001;90:492-8.

27. Brooklyn TN, Di Mambro AJ, Haslam N. Patients over 45 years with iron deficiency require investigation. Eur J Gastroenterol Hepatol. 2003;15:535-8.

28. Larner AJ. Visual failure caused by Vitamin B12 deficiency optic neuropathy. Int J Clin Pract. 2004;58(10):977-8.

29. Vidal-Alaball J, Butler CC, Potter CC. Comparing costs of intramuscular and oral vitamin B12 administration in primary care: a cost minimization analysis. Eur J Gen Pract. 2006;12(4):169-73.

30. DeZern AE, Brodsky RA. Clinical management of aplastic anemia. Expert Review of Hematology. 2014;4(2):221-30.

31. Hoffbrand V, Provan D. ABC of clinical haematology: macrocytic anaemias. $\mathrm{Br}$ Med J. 1997;314:430-3.

32. Hesdorffer CS, Longo DL. Drug-induced megaloblastic anemia. N Engl J Med. 2015;373:1649-58. 